\title{
AS RELAÇÕES POLIAFETIVAS, OMISSÃO REGULATÓRIA E SEUS REFLEXOS JURÍDICOS NAS QUESTÕES DE DIREITO PREVIDENCIÁRIO
}

POLY-FEASIBLE RELATIONS, REGULATORY OMMISSION AND ITS LEGAL REFLECTIONS ON ISSUES OF PRIVILEGED RIGHTS

Danilo Henrique Nunes ${ }^{1}$

UNAERP

Lucas de Souza Lebfeld

UNAERP

\section{Resumo}

O conceito tradicional de família e os modelos familiares embasados pelo Princípio da Monogamia vem cada vez mais perdendo sua validade jurídica, uma vez que é notório que o Direito deve produzir efeitos que conduzam ao bem-estar dos indivíduos e à preservação dos princípios estabelecidos pelo constituinte. As questões envolvendo as relações familiares passaram recentemente por uma série de discussões e pesquisas acerca da possibilidade de reconhecimento das uniões homoafetivas como entidade familiar passam por uma nova perspectiva: o reconhecimento das uniões poliafetivas como entidade familiar. O presente estudo parte das questões envolvendo o novo conceito de família e das relações poliafetivas, apresentando uma omissão regulatória generalizada acerca de tal tema, que implica em uma série de reflexos acerca dos Direitos e Deveres das pessoas que se encontram em relacionamentos compostos por três pessoas ou mais, dando ênfase para tais reflexos no âmbito previdenciário, a partir do método hipotético-dedutivo. Serão contrapostos achados na doutrina jurídica e na jurisprudência brasileira, bem como em questões encontradas em periódicos relacionadas ao tema, uma vez que o tema em questão vem tão somente recentemente ocupando estudiosos e pesquisadores do tema, sendo necessária a produção de novas conclusões nesse sentido.

Palavras-chave

Relações Poliafetivas. Omissão Regulatória. Direito Previdenciário.

${ }^{1}$ Danilo Henrique Nunes. Advogado com especialização em Direito Processual Civil e Didática para Ensino Superior pelo Centro Universitário da Fundação Educacional de Barretos e em Direito Constitucional pela Faculdade de Direito Damásio de Jesus. Aluno bolsista do CAPES no curso de Mestrado em Direitos Coletivos e Cidadania da Universidade de Ribeirão Preto - área de concentração: Direitos Coletivos e Cidadania, na linha de pesquisa - Concreção dos Direitos Coletivos e Cidadania. Professor do Centro Universitário da Fundação Educacional de Barretos - UNIFEB e do Centro Universitário Estácio de Ribeirão Preto. dhnunes@hotmail.com

2 Professor pós-doutor e orientador do programa de Mestrado em Direitos Coletivos e Cidadania da Universidade de Ribeirão Preto. Advogado e professor universitário. lehfeldrp@gmail.com 
Revista da Faculdade Mineira de Direito | v.21 N.41 | 226

\begin{abstract}
The traditional concept of family and family models based on the Principle of Monogamy is increasingly losing its legal validity, since it is well known that law must produce effects that lead to the well-being of individuals and to the preservation of the principles established by the constituent. The issues surrounding family relations have recently undergone a series of discussions and research about the possibility of recognition of homoaffective unions as a family entity. They take a new perspective: the recognition of poly-affective unions as a family entity. The present study starts from the questions surrounding the new concept of family and poly-affective relations, presenting a generalized omission on this subject, which implies a series of reflections about the Rights and Duties of people who are in relationships composed of three persons or more, giving emphasis to such reflexes in the social security scope, from the hypothetico-deductive method. Findings will be contrasted in legal doctrine and Brazilian jurisprudence, as well as in issues found in periodicals related to the subject, since the subject in question has only recently occupied scholars and researchers of the subject, being necessary the production of new conclusions in this sense.
\end{abstract}

Keywords

Poliaffective Relationships; Regulatory Omission; Social Security Law.

\title{
1 INTRODUÇÃO
}

Recentemente, vem sendo fomentados debates e estudos que envolvem um 'novo modelo' de união: aquele composto por mais de duas pessoas - as denominadas relações poliafetivas. Essas questões permeiam o meio social, sobretudo após o lavramento de três escrituras públicas que aceitaram tal modelo de união, todavia, sem necessariamente produzir efeitos jurídicos contundentes nesse sentido.

É notório o entendimento de que o Direito deve acompanhar as transformações sociais. Um exemplo disso que costumeiramente é operado juntamente com as questões envolvendo os aspectos jurídicos das relações poliafetivas: o caso das relações homoafetivas, que baseia e redesenha o conceito de família a partir de aspectos como a afetividade e a continuidade, tendo como base a liberdade e o princípio da dignidade da pessoa humana - aspectos recorrentes também no âmbito da união poliafetiva e de suas possibilidades.

O presente artigo científico busca uma ampla explanação acerca das relações poliafetivas, partindo do pressuposto da evolução do conceito de família de aspectos tradicionais até um novo conceito pautado pela 
Revista da Faculdade Mineira de Direito | V.21 N.41 | 227

efetividade, realizando uma breve caracterização das relações poliafetivas sob a perspectiva das uniões estáveis. Entretanto, não se trata de um estudo com ênfase em definições conceituais, mas sim de aspectos que se relacionam ao contexto jurídico.

Outrossim, é aprofundada no presente estudo a questão da omissão regulatória das relações poliafetivas, bem como os efeitos jurídicos de tal omissão, com ênfase nas questões de Direito Previdenciário. Destaca-se, entretanto, que sobretudo no âmbito do Direito Previdenciário, os especialistas têm dedicado poucos esforços sobre o assunto, de modo que novas conclusões precisam ser alcançadas nesse sentido, uma vez que o enfoque dos estudos que advém das relações poliafetivas costuma ter seu cerne em questões que envolvem tão somente o Direito de Família, ignorando a importância do tópico para outras áreas das Ciências Jurídicas.

\section{CONCEITO DE FAMÍLIA: DO TRADICIONAL ATÉ ÀS RELAÇÕES POLIAFETIVAS}

De acordo com Valle (2009) a entidade familiar é tradicionalmente constituída pela figura do esposo e da esposa, sendo posteriormente ampliada com o nascimento dos filhos. Ao se casarem, os filhos não rompem o vínculo familiar com seus pais e, por sua vez, se casam e tem filhos, aumentando ainda mais a família. Assim, seguindo a concepção tradicional a família pode ser formada por laços sanguíneos (descendência) e por afinidade (união e casamento).

De acordo com Pereira (2004), na medida em que a própria sociedade evoluiu, as famílias sentiram a necessidade de proteção por meio de leis, as quais culminaram no surgimento do Direito de Família, que regulou as relações familiares bem como trouxe os mecanismos legais para solucionar os conflitos advindos de tais relações. Para o autor, a necessidade de regulação estatal e jurídica para as instituições familiares diz respeito à própria evolução do conceito de família.

Para Szymanski (2005) a partir da proteção do Estado para a sociedade familiar surgiu a igualdade de condições entre os cônjuges para o exercício do poder familiar de forma equilibrada. Dado tal fato, passou a haver uma reconfiguração no conceito de família, concebendo-a como um instituto que pode ser constituído por pessoas que moram em um mesmo 
Revista da Faculdade Mineira de Direito | v.21 N.41 228

lar, com base nos vínculos afetivos independente de ser contraído matrimônio, visto que a própria $\mathrm{CRFB/88} \mathrm{já} \mathrm{traz} \mathrm{a} \mathrm{união} \mathrm{estável} \mathrm{como}$ forma de entidade familiar.

Assim, o constituinte de 1988 priorizou o instituto familiar como uma base social, admitindo novas formas e novos valores sociais, a partir da consagração de princípios como a dignidade da pessoa humana, para assegurar o tratamento prioritário às crianças e aos adolescentes de acordo com seu bem-estar, igualdade e valorização. Fachin (2011) aponta que a partir da evidenciação de um grande número de famílias não matrimonializadas (como nos casos de uniões estáveis e de famílias monoparentais) fora consagrada a abertura de um novo conceito familiar, baseado nos vínculos afetivos e familiares, indo além de um modelo único de família caracterizado pelo matrimônio e pela prole.

De tal modo, o afeto e a busca pela felicidade e bem-estar das pessoas promoveu uma alteração social e jurídica do conceito daquilo que contemplamos como família na atualidade. A partir dessa perspectiva, deve ser considerada a importância dos vínculos familiares e afetivos e da importância de tais vínculos de acordo com os preceitos da contemporaneidade.

Para Lemos (2017) a importância de tais vínculos é refletida justamente na estruturação psíquica e social dos seres humanos, visto que o vínculo familiar ocorre mediante ao investimento afetivo e a sensibilidade materna para responder os sinais e comunicações da criança. As primeiras relações da criança para o seu desenvolvimento, de acordo com a autora, devem ser analisadas a partir da teoria do apego, que descreve as relações do bebê com a mãe ou o cuidador desde o seu nascimento até os seis anos de idade. A criança, a partir do relacionamento com a pessoa responsável por seus cuidados, passa a desenvolver o modo através do qual serão estabelecidas as suas futuras relações, de modo que os cuidados e a afetividades nos vínculos familiares são importantes para um desenvolvimento adequado da sensibilidade da criança e do modo através do qual ela percebe a si mesma e às pessoas que a cercam.

Nesse sentido:

As manifestações de afeto, principalmente mãe/filho são decisivas para a formação da personalidade e terão importante influência nas relações sociais ao longo da 
Revista da Faculdade Mineira de Direito | v.21 N.41 229

vida, sendo assim, determinante na formação da estrutura emocional do indivíduo. Sabendo que a afetividade faz parte de todo o desenvolvimento estrutural e psicológico do ser humano, e que sem ela, este não se desenvolve plenamente, é de extrema relevância demonstrarmos a importância do afeto na construção da base da personalidade nos primeiros anos de vida, considerando que aquilo que acontece ao indivíduo neste período irá refletir-se na adolescência e na fase adulta. As impressões registradas no inconsciente, pela presença ou ausência das relações afetivas entre pais e filhos, podem causar graves transtornos afetivos e emocionais às crianças (BAIRROS et al. Apud LEMOS, 2017, p. 2).

Para Abuchaim et al. (2016) a importância dos vínculos familiares e afetivos não se encerra aos seis anos de idade (primeira infância) para o desenvolvimento saudável das crianças. Para os autores, os adultos são concebidos durante toda a infância como fontes de segurança e acolhimento pelas crianças, de modo que boas experiências afetivas irão influenciar positivamente no decorrer da vida do indivíduo e em seu comportamento. No mesmo sentido, os autores ainda apontam que os vínculos familiares formados a partir da efetividade não se restringem tão somente aos aspectos parentais (ou seja, em torno da criança), mas para todos os indivíduos que partilham do afeto.

Entretanto, a maior parte dos estudos que abordam o afeto como um elemento determinante para os conceitos sociais e jurídicos de família, não abordam as relações poliafetivas. Para Vechiatti (2016) é ilegítima socialmente e constitucionalmente a tradição do reconhecimento jurídico e familiar da união poliafetiva, uma vez que se entende que a imposição da monogamia como uma norma cogente do Direito brasileiro é algo descabido, justificando o reconhecimento da união poliafetiva consensual e não-opressora como uma entidade familiar constitucionalmente protegida. Assim:

(...) sempre teremos uma família quando houver uma comunhão plena de vida e interesses, de forma pública, contínua e duradoura (...) Nesse sentido, considerando 
Revista da Faculdade Mineira de Direito | v.21 N.41 230

que a união poliafetiva se enquadra neste conceito ontológico-constitucional de família e considerando a inexistência de motivação lógico-racional que justifique sua discriminação relativamente à união monoafetiva, tem-se que ela se enquadra como entidade familiar, ante o caráter exemplificativo do rol dos parágrafos do artigo 226 da Constituição Federal (VECHIATTI, 2016, p. 30).

Ora, ainda que não haja um consenso absoluto entre os autores que abordam a possibilidade de conceituação jurídica da família estendível aos relacionamentos poliafetivos, há o embasamento teórico necessário para que de fato essas relações possam ser contempladas nesse sentido e, de tal modo, devem ser protegidas pelo Estado.

Chatter (2015) também buscou aprofundar as possibilidades e não possibilidades de reconhecimento jurídico no âmbito das uniões poliafetivas. Para a autora, o Direito deve sempre se adaptar às transformações sociais, com mudanças que ocorrem justamente para melhorar a tutela de família, de modo que os conceitos tradicionais passam a ser rompidos para dar espaço a interpretações mais amplas de família, com um conceito atual que atualmente abrange a família como base da sociedade, tutelada pelo Estado e que acolhe diversas entidades familiares, como a união estável. A autora faz uso justamente do exemplo dos casais homoafetivos e das uniões estáveis para verificar que o Direito deve sempre contemplar um conceito evolutivo de família, uma vez que esses casais até então não eram reconhecidos como entidade familiar.

Compreender os casais homoafetivos como um núcleo familiar advém do entendimento de que a nossa Carta Magna deixa margem de interpretação aberta para as possibilidades de família. O artigo $226 \mathrm{da}$ CRFB/88 não determina qualquer condição excludente para que uma família seja constituída, de modo que anteriormente a redação da Lei Maior definia que o casamento era o vínculo que seria capaz de constituir uma entidade familiar. Ora, não há possibilidade constitucional que exclua um casal homoafetivo das possibilidades de que estes se constituam enquanto família. Essa mesma prerrogativa se faz valer para os relacionamentos poliafetivos. 
Revista da Faculdade Mineira de Direito | v.21 N.41 231

Dentro desse contexto:

Ocorre que o primado da monogamia não é um princípio expresso na Constituição, é algo meramente cultural. A bigamia, por sua vez, prevê punição aos casados, o que não é o caso, e mesmo se associada à união estável, não se aplicaria, em virtude da inexistência de mais do que uma união. Quanto à dignidade da pessoa humana, não há violação e sim sua reafirmação, já que cada um busca a felicidade da forma que deseja e todos têm o direito de constituir uma família, independente de como seja seu arranjo. Além disso, deve-se prezar os vínculos formados pelo afeto, mesmo que seja o caso de múltiplo afeto (CHATTER, 2015, p. 63).

Partindo de tal pressuposto, entende-se que os argumentos contrários a um conceito de família poliafetiva não se sustentam, uma vez que a monogamia não é um princípio expresso de modo tácito pela constituição, mas sim um aspecto da nossa organização em sociedade. $\mathrm{O}$ fato da monogamia ser o modelo mais comum de entidade familiar na sociedade brasileira, não significa que o Estado possa impô-lo a todos os indivíduos, levando em consideração que seu principal objetivo é a promoção do bem comum, respeitando princípios da liberdade, da não discriminação, da segurança jurídica e da dignidade da pessoa humana.

Com base nos ensinamentos de Vechiatti (2016, p. 30) em sua investigação acerca da união poliafetiva como entidade familiar constitucionalmente protegida, entende-se que "Família conjugal é toda união pautada pela afetividade, estabilidade, ostensibilidade, publicidade e estruturação psíquica familiar" e, de tal modo, havendo comunhão de vida e interesses de modo público, contínuo e duradouro, há uma entidade familiar. Os relacionamentos poliafetivos, outrossim, quando delimitados por essas características, podem sim ser considerados enquanto entidades familiares. As questões envolvendo os vínculos e a afetividade são indispensáveis para tal compreensão.

De fato, o conceito de família no âmbito social e jurídico sempre acompanhou as mudanças sociais, não se atendo tão somente aos termos e aspectos tradicionais. Diante disso, há uma ampla possibilidade de aceitação 
Revista da Faculdade Mineira de Direito | v.21 N.41 232

das relações afetivas enquanto entidades familiares, nos termos e prerrogativas aqui expostos. A partir de tais questões e da aceitabilidade das relações poliafetivas como entidades familiares, torna-se possível aprofundar o conceito de relacionamento poliafetivo, para que possam ser aprofundados os aspectos jurídicos nesse sentido.

\section{RELAÇÕES POLIAFETIVAS: BREVE CARACTERIZAÇÃO E A OMISSÃO REGULATÓRIA}

O presente capítulo abordará o conceito já apresentado acerca das relações poliafetivas, para que seja possível direcionar o tema aos aspectos envolvendo a omissão regulatória e os reflexos jurídicos no âmbito das questões que envolvem o Direito Previdenciário. Essa caracterização envolve justamente as questões anteriormente apresentadas, como o novo conceito de família pautado pela afetividade nos vínculos familiares e sobre a não imposição da monogamia como modelo único de relacionamento.

De acordo com Meira (2015) o poliamor pode ser definido como uma relação conjugal que envolve de modo simultâneo mais de duas pessoas, de modo consensual, sendo que os envolvidos vivem como uma única família em comunhão de objetivos de vida. Para a configuração da relação afetiva, segundo a autora, é indispensável que haja uma convivência entre mais de duas pessoas, cuja união seja pública, contínua, duradoura, consensual e admitida por todos os envolvidos, os quais devem ter como objetivo primordial a constituição de uma família. A autora ainda complementa:

Importante diferenciar o poliamor da poligamia, muito comum nos países de religiões predominantemente mulçumanas, onde somente o homem pode ter mais de uma mulher, sem que haja prévio consentimento das mulheres já envolvidas com este. No poliamor há uma relação em que deve prevalecer o consentimento de todas as pessoas envolvidas, de forma que haja amor e relação de afeto entre todos os seus integrantes, refletindo uma ideia de cumplicidade, igualdade e concordância a partir de uma vontade própria e livre. De mesma forma, não se pode confundir poliamor com família paralela, já que neste caso há traição, ocultação 
Revista da Faculdade Mineira de Direito | v.21 N.41 233

e dissimulação, sem que haja concordância de um dos cônjuges e configurando lesão ao dever jurídico da fidelidade (MEIRA, 2015, p. 3).

Para os objetivos propostos pelo presente estudo, as uniões poliafetivas serão concebidas tão somente como aquelas nas quais se fazem valer as condições expressas no artigo 1723 do Código Civil (estabilidade, convivência pública, continuidade, durabilidade e objetivos de constituição familiar), de modo a não abarcar a família poliafetiva não estável. Todos esses elementos devem estar presentes para a configuração das relações poliafetivas no âmbito familiar, uma vez que deve ser caracterizada a união estável nos termos impostos pelo legislador civil.

Diante de tal caracterização, é indispensável aprofundar questões envolvendo a omissão regulatória acerca das relações poliafetivas. De acordo com Pereira et al. (2016) o direito anseia pela justiça e pela igualdade e, portanto, deve solucionar as soluções não previstas pelo ordenamento jurídico pátrio. Quando há omissão regulatória à proteção das relações afetivas, há desaforo ao Princípio da Dignidade e o risco de produzir injustiça. O Direito, segundo a autora, deve proteger sempre a essência e não a forma, ainda que para isto seja necessário arranhar o dito Princípio da Monogamia.

Moscalewsky (2016) aponta que das relações familiares não decorrem tão somente direitos, mas também deveres. Quando há ausência e ingerência estatal para algumas modalidades de família, deve ser reconhecida a proteção das pessoas que as compõe, de modo que a omissão legal não significa uma liberdade desmedida, pois o limite de tal omissão é a responsabilidade. $\mathrm{O}$ autor complementa que

o reconhecimento da pluralidade das entidades familiares importa em uma grande conquista, não apenas por conta dos direitos que adquiriram as pessoas que compõe entidades familiares não conformadas com os parâmetros mais comuns, mas também em decorrência da possível responsabilização individual de seus membros em relação aos demais companheiros e filhos. A solidariedade, existente em todas as famílias, pode traduzir-se em responsabilidade. Seja responsabilidade por cuidados durante a união, seja 
Revista da Faculdade Mineira de Direito | v.21 N.41 234

pelo pagamento de alimentos quando do término do relacionamento, fato é que, reconhecido o vínculo familiar, haverá responsabilidade de uns para com os outros (MOSCALEWSKY, 2016, p. 31).

Segundo Goedert (2016) a institucionalização estatal da monogamia enquanto um padrão que deve ser seguido pelos indivíduos resulta na restrição de liberdades nas relações familiares. Os deveres de fidelidade, respeito, amor, afeto, carinho, amizade e sexo são intrínsecos do exercício da liberdade e da intimidade de cada ser humano, não devendo encontrar qualquer tipo de projeção no interesse geral. O que deve importar no âmbito dos outros modelos familiares é assegurar aos sujeitos seus direitos fundamentais e que sejam criadas as condições para o exercício de sua liberdade, as quais não veem sendo oportunizadas aos adeptos ao poliamor, em razão da omissão estatal quando ao seu reconhecimento.

Nesse sentido:

(...) por ser a união poliafetiva permeada por valores que garantem o pleno desenvolvimento pessoal e social de seus participantes, como a solidariedade, liberdade, igualdade, respeito, honestidade, confiança, lealdade, afeto e vontade de partilhar de um projeto de vida valores estabelecidos e almejados pela Carta Magna de 1988 quando se trata de família - que a relação tema desse trabalho merece reconhecimento. $O$ poliamorismo, enfim, respeita e garante a dignidade de todos seus membros, o que consubstancia, em derradeiro, o seu reconhecimento jurídico e a concessão de direitos e garantias decorrentes da vida em comum inerentes a qualquer ente que compõe família - aos seus integrantes (GOEDERT, 2016, p. 91).

Para aprofundar as questões aqui expostas, no capítulo seguinte será realizada uma ampla análise jurisprudencial e doutrinária das relações poliafetivas sob as perspectivas do ordenamento jurídico, para que por fim as conclusões possam refletir nas questões de Direito Previdenciário. 
Revista da Faculdade Mineira de Direito | v.21 N.41 235

\section{ANÁLISE JURISPRUDENCIAL E DOUTRINÁRIA ACERCA DA UNIÃO POLIAFETIVA PERANTE O ORDENAMENTO JURÍDICO BRASILEIRO}

De acordo com Figueiredo e Fermentão (2015) a imposição do princípio da monogamia não tão somente busca padronizar as relações familiares, mas também negar piamente juridicidade às uniões poliafetivas. O simples detalhe de que o constituinte de 1988 não contempla o sistema monogâmico enquanto princípio deveria invalidar a tese (que não se sustenta por não ter amparo jurídico no ordenamento vigente). Para os autores, a monogamia perdeu a sua importância jurídica e na atualidade representa tão somente uma regra de convivência (a qual não deve ser imposta a todos), de modo que os vínculos familiares e o novo conceito de família dão respaldo legal para aceitar as uniões poliafetivas como entidades familiares, o que torna injustificável que o Direito e o Estado se omitam nesse sentido.

Destarte, se inicia a análise jurisprudencial da Apelação Cível $n^{\circ}$. 0302436-02.2016.8.24.0082, do TJSC, sob relatoria do desembargador Henry Pedry Junior, julgada em dezembro de 2017:

Ementa: APELAÇÕES CÍVEIS. CIVIL E PROCESSUAL CIVIL. EMBARGOS DE TERCEIRO. AÇÃO DECLARATÓRIA E CONSTITUTIVA. UNIÃO ESTÁVEL. PARTILHA. - PROCEDÊNCIA PARCIAL NA ORIGEM. RECURSO DOS EMBARGADOS. (1) PRELIMINAR.

JULGAMENTO ANTECIPADO. CERCEAMENTO. NÃO CONFIGURAÇÃO. DILAÇÃO. DESNECESSIDADE.

Nesse caso em questão, a conclusão alcançada pelo tribunal delimitou que não se confunde com as chamadas uniões estáveis poliafetivas, poliamorosas e de poliamor, em que não se têm uniões estáveis plúrimas, múltiplas, simultâneas e paralelas, mas sim uma única relação afetiva com mais de 2 membros cuja assentada jurídica é idêntica àquela da união estável bilateral, ainda que sem posicionamento jurisprudencial, uma 
Revista da Faculdade Mineira de Direito | v.21 N.41 236

vez que é defendida pela doutrina jurídica em âmbito nacional. Os votos contemplaram que assim como o fundamento de acolhida da união estável homoafetiva que a proteção estatal se dirige à tutela do afeto consubstanciado na solidariedade familiar é aplicável no âmbito das uniões poliafetivas, valendo-se da mesma prerrogativa, independentemente de sua composição numérica.

Ora, a jurisprudência recente já admite a possibilidade de reconhecimento das uniões poliafetivas como entidades familiares, uma vez que atendidos os pressupostos já apresentados no presente estudo. Tal entendimento, entretanto, não é majoritário entre os tribunais brasileiros, mas abre um precedente interessante para a aplicabilidade dessa tendência jurídica. De fato, os esforços dos doutrinadores em aprofundar questões envolvendo as relações poliafetivas são apontados como elementos a serem acatados pela jurisprudência recente.

A jurisprudência a ser analisada em seguida se dá em Agravo Em Recurso Especial nº 1.008.399 - DF (2016/0286105-0), cuja ementa está apresentada abaixo:

Ementa: AGRAVO EM RECURSO ESPECIAL. PROCESSUAL CIVIL (CPC/1973). AÇÃO DE RECONHECIMENTO E DISSOLUÇÃO DE UNIÃO ESTÁVEL 'POST MORTEM'. UNIÃO ESTÁVEL DESCARACTERIZADA. REVISÃO. IMPOSSIBILIDADE. SÚMULA 07/STJ. AGRAVO DESPROVIDO.

Trata-se de um agravo em recurso especial promovido por autora diante do reconhecimento de união estável, caracterizada pela convivência duradoura, pública e contínua com falecido. A situação vivida pelo falecido, na concepção dos julgadores, se aproxima da situação denominada família eudemônica, que efetivamente aceita a união estável - ou de uma situação que se traduz em nítida situação de poliamor, ou seja, na possibilidade de coexistirem duas ou mais relações afetivas paralelas, conhecidas e acatadas pelos partícipes, em uma relação múltipla. As questões envolvendo a poliafetividade e seus aspectos correlatos, assim, estão amplamente presentes em julgamentos recentes nos tribunais, sobretudo nos dois últimos anos. 
Revista da Faculdade Mineira de Direito | v.21 N.41 237

Fell e Sanches (2016) também buscaram aprofundar o contexto das relações afetivas sob uma ótica doutrinária e jurisprudencial. Os autores citam que em 2012, na cidade de Tupã/SP foi lavrada a primeira escritura pública de uma união denominada como poliafetiva pela tabeliã responsável, uma vez que tal relação se dava a partir de uma relação afetiva entre mais de dois componentes. Posteriormente, outras uniões também foram caracterizadas como afetivas: uma contando com a relação afetiva entre três mulheres no ano de 2015 e outra entre duas mulheres em um homem em 2016, ambas na cidade do Rio de Janeiro/RJ.

Em sua análise jurisprudencial, os autores supramencionados apontaram que o Tribunal de Justiça do Estado de Pernambuco reconheceu união paralela, a partir dos princípios modernos do direito de família, ampliando a visão da entidade familiar. São levantadas concepções que envolvem a aceitação dos novos modelos de família, sobretudo envolvendo casais homoafetivos. Nesse ponto, devemos nos ater ao que determina a jurisprudência. Um marco jurisprudencial exercido acerca da adoção por casais homoafetivos fora julgado pelo Tribunal de Justiça do Rio Grande do Sul (TJRS) há mais de uma década atrás, objetivando o seguinte entendimento:

EMENTA: APELAÇÃO CÍVEL. ADOÇÃO. CASAL FORMADO POR DUAS PESSOAS DE MESMO SEXO. POSSIBILIDADE. Reconhecida como entidade familiar, merecedora da proteção estatal, a união formada por pessoas do mesmo sexo, com características de duração, publicidade, continuidade e intenção de constituir família, decorrência inafastável é a possibilidade de que seus componentes possam adotar. Os estudos especializados não apontam qualquer inconveniente em que crianças sejam adotadas por casais homossexuais, mais importando a qualidade do vínculo e do afeto que permeia o meio familiar em que serão inseridas e que as liga aos seus cuidadores. É hora de abandonar de vez preconceitos e atitudes hipócritas desprovidas de base científica, adotando-se uma postura de firme defesa da absoluta prioridade que constitucionalmente é assegurada aos direitos das crianças e dos adolescentes (art. 227 da Constituição 
Revista da Faculdade Mineira de Direito | v.21 N.41 238

Federal). Caso em que o laudo especializado comprova o saudável vínculo existente entre as crianças e as adotantes. NEGARAM PROVIMENTO. UNÂNIME. (SEGREDO DE JUSTIÇA) (Apelação Cível No 70013801592, Sétima Câmara Cível, Tribunal de Justiça do RS, Relator: Luiz Felipe Brasil Santos, Julgado em 05/04/2006).

Analisando de maneira clara o entendimento jurisprudencial adotado pelo TJRS no caso concreto, podemos observar que há possibilidade de reconhecimento dos casais homoafetivos como uma entidade familiar, de modo que não deve haver qualquer distinção em face dos casais tradicionais em união estável. Esse mesmo entendimento deve valer para as relações poliafetivas, que no presente momento começam a levantar intensos debates no âmbito jurídico, entretanto, há pouca informação encontrada acerca dos entendimentos jurisprudenciais que abordem em caráter objetivo o reconhecimento da poliafetividade como um modelo de entidade familiar.

No estudo de Fell e Sanches (2016) ao analisar a escritura pública lavradada no Município de Tupã, são citados pontos que afirmam que a mesma seria nula, nos termos do artigo 166 do Diploma Civil, que proíbe uniões poligâmicas, e à concepção de que tal escritura não teria eficácia, visto que o constituinte atribuiu visão monogâmica à união estável. Entretanto:

(...) ainda que assim não fosse e, considerando uma remota chance de subsistir a declaração de vontade manifestada em uma escritura pública de união poliafetiva, ter-se-ia, no máximo, a configuração de uma sociedade de fato, com efeitos meramente patrimoniais, sem reflexos sucessórios, previdenciários, alimentares e familiares, tratando-se apenas no direito obrigacional (...) Ou seja, jamais poderia aquela ser enquadrada perante o direito de família brasileiro (FELL; SANCHES: 2016, p. 9).

Conforme apontado anteriormente, não há previsão tácita na Constituição que proíbe as relações poliafetivas e uma parcela majoritária 
Revista da Faculdade Mineira de Direito | v.21 N.41 | 239

da doutrina a assume como entidade familiar a partir da consumação de união estável. Não há, entretanto, um consenso absoluto entre doutrinadores e juristas nesse sentido, sobretudo pelo fato de que determinados estudiosos do Direito deixam de lado os aspectos piamente jurídicos para emitir opiniões acerca daquilo que deveria ser adequado e moral para a sociedade, numa tentativa de impor a manutenção do Princípio da Monogamia.

Fica assim caracterizada uma omissão regulatória generalizada acerca das relações poliafetivas dentro desse contexto.

\section{REFLEXOS JURÍDICOS NAS QUESTÕES DE DIREITO PREVIDENCIÁRIO DIANTE DA OMISSÃO REGULATÓRIA DAS RELAÇÕES POLIAFETIVAS}

Segundo Rosa e Oliveira (2017) os diferentes tópicos e a omissão regulatória acerca das relações poliafetivas vem levantando uma série de controvérsias em âmbito nacional, uma vez que envolve terceiros, direitos sucessórios, previdenciários e de família, o que clama por uma regulamentação do tema, devido a peculiaridade da situação acerca das uniões poliafetivas enquanto um fato social.

De acordo com Martinez (2016) os aspectos relacionados à poliafetividade tem provocado pouco interesse dentre os especialistas de Direito Previdenciário, sobretudo pelo fato de que os casos oficiais de poligamia são raros e com poucos desdobramentos na ordem social, devendo ser suscitados como se sucedeu com situações envolvendo homossexuais, transexuais e transgêneros, como uma mera experiência individual. Sobre as fontes formais envolvendo as relações poliafetivas, o autor aponta que:

Não existem fontes formais positivadas sobre poligamia. Somente entendimentos doutrinários e escoteiras decisões judiciais que cuidam de sua expressão informal. Os cartórios ou tabelionatos do país não estão autorizados a inscrever esse tipo de união como um casamento civil. Os interessados podem registrar uma escritura de vontade de assim viverem, principalmente pensando nos desdobramentos futuros 
Revista da Faculdade Mineira de Direito | v.21 N.41 | 240

da relação jurídica (...) O novo Código Civil silencia a respeito; não há tratamento do assunto, embora a codificação seja de 2002. Quando de debates patrimoniais, os juízes não terão esse farol para ajudá-lo nesse labirinto jurídico. Terão de se utilizar da analogia e da exegese teleológica. Quem se verá em palpos de aranha é o INSS, sempre um dos primeiros a ser acionado, com algum pedido de inscrição de dependentes ou até mesmo de um requerimento da pensão por morte ou do auxílio-reclusão (MARTINEZ, 2016, p. 9).

Há pouco conteúdo delimitando os reflexos da omissão regulatória nas questões de Direito Previdenciário sob a perspectiva das relações poliafetivas. Entretanto, uma análise realizada por Santos (2008?) apontou que benefícios como o Benefício Previdenciário da Pensão por Morte, que segue aspectos como uma instituição nromalizada por uma série de regulamentos de filiação e aliança aceitos pelos membros passa por temas envolvendo aspectos como as relações poliafetivas, a monogamia, dentre outros.

Um artigo publicado por Cardoso (2017) pelo fato de ainda não haver uma regulamentação acerca das uniões poliafetivas, o Poder Judiciário deve optar entre dois caminhos opostos: declarar sua existência e tornar efetivos todos os efeitos decorrentes do contrato ou declarar a inexistência da entidade familiar composta por mais de duas pessoas. Para a autora, é indispensável aguardar e observar o comportamento do Direito e da sociedade, uma vez que o reconhecimento legal trará consequências tanto para o direito das sucessões quanto para o direito previdenciário.

Fell e Sanches (2016), no mesmo sentido, apontam que a omissão regulatória permite que as relações/uniões poliafetivas tão somente sejam contempladas como a configuração de uma sociedade de fato, o que contemplaria efeitos patrimoniais, mas sem reflexos sucessório, previdenciário, alimentares e familiares, estando tão somente enquadrada no âmbito do direito obrigacional.

Para Carvalhal (2017) o reconhecimento do Supremo Tribunal Federal acerca da juridicidade do afeto nas relações familiares diante do acatamento das 'famílias simultâneas' é um provável precedente a ser fixado 
Revista da Faculdade Mineira de Direito | v.21 N.41 241

e que pode influenciar fortemente o reconhecimento das entidades familiares poliafetivas. Os tribunais na atualidade já vêm reconhecendo efeitos previdenciários às concubinas (situações em que a esposa ou companheira não tinha conhecimento acerca da existência de outra família concomitante), de modo que tal linha de aceitação supõe o reconhecimento igualmente acerca do poliamor, para privilegiar a liberdade das partes envolvidas.

O reconhecimento de famílias simultâneas e seus efeitos previdenciários e patrimoniais, de tal forma, contribui de maneira significativa para que ocorra o reconhecimento jurídico das famílias compostas por relações poliafetivas, equivalendo-as aos patamares das uniões estáveis contempladas pelo ordenamento jurídico pátrio e pelo Direito Previdenciário, tornando sanadas as questões envolvendo aspectos previdenciários como benefício após morte e outros aspectos correlados.

\section{CONSIDERAÇÕES FINAIS}

O conceito tradicional de família, a imposição do princípio da monogamia e a imposição de um modelo único e monogâmico de relação familiar não abarca preceitos como a afetividade nos vínculos familiares e passa tão somente por um aspecto cultural de organização das relações sociais e da sociedade como um todo, e não deve influir de modo contundente em questões jurídicas.

O presente estudo buscou realizar uma ampla análise acerca das relações e uniões poliafetivas, dando ênfase para a omissão regulatória nesse sentido (amplamente observada durante a análise jurisprudencial) e para os efeitos de tal omissão diante de questões que envolvem o Direito Previdenciário.

Conforme apontado, importantes passos foram dados recentemente nesse sentido. No ano de 2017, o Supremo Tribunal Federal passou a aceitar as 'famílias simultâneas' como uma entidade familiar para fins jurídicos, bem como passou a assegurar benefícios sucessório e previdenciários mais amplos dentro desse contexto. É uma tendência jurídica, de tal forma, que as relações poliafetivas (ainda raras no sentido de oficialização na sociedade brasileira) passem para o mesmo caminho. 
Revista da Faculdade Mineira de Direito | v.21 N.41 | 242

Dentre os autores que compuseram o desenvolvimento do presente estudo, não há consenso claro acerca da legitimidade das uniões poliafetivas enquanto uniões estáveis e modelos familiares. Entretanto, o entendimento majoritário do qual o autor do presente estudo compartilha é de que não há no ordenamento jurídico pátrio, nenhum veto expresso para a concretização de direitos destinados às pessoas que optam ou se veem dentro de um contexto que envolve o dito poliamor. De fato, a obrigação principal do acessório é cumprir a função de proporcionar o bem-estar coletivo e individual, assegurando que sejam cumpridos princípios como a Liberdade Individual. Caso o Estado imponha um modelo de relação familiar que retire a liberdade de escolha das pessoas que se encontram nas relações poliafetivas (ou seja, a impor o princípio da monogamia) o mesmo não estaria cumprindo sua finalidade primordial, indo, inclusive, contra o princípio da dignidade humana.

Especificamente no âmbito dos reflexos jurídicos da omissão regulatória acerca do reconhecimento das uniões poliafetivas, entende-se que há muita nebulosidade e uma série de lacunas a serem preenchidas pela doutrina e pela jurisprudência. De fato, o fim de tal omissão regulatória culminaria em uma série de efeitos sociais e jurídicos, os quais não são conhecidos até o momento do desenvolvimento do presente estudo.

O presente artigo científico se ocupou de uma questão bastante importante na atualidade, buscando a realização de uma ampla análise dos aspectos jurídicos e sociais das relações poliafetivas.

Entretanto, na medida que o Direito vai acompanhando a consolidação desse novo modelo familiar, é indispensável que os estudiosos da área concentrem esforços visando uma melhor delimitação de tais aspectos.

\section{REFERÊNCIAS}

ABUCHAIM, B et al. Importância dos vínculos familiares na primeira infância: estudo II. 1. ed. -- São Paulo: Fundação Maria Cecilia Souto Vidigal - FMCSV, 2016.

CARDOSO, M. União Poliafetiva - Conceito e Reflexos da Polêmica União.

3/jul/2017.

Disponível

em 
Revista da Faculdade Mineira de Direito | v.21 N.41 243

<www.soupnews.com.br/blogdamonica/uniao-poliafetiva-conceito-ereflexos-da-polemica-uniao/> Acesso: Fev/2018.

CARVALHAL, A.P. Supremo reconhece a juridicidade do afeto nas relações familiares. Revista Consultor Jurídico, 1 de abril de 2017. Disponível em < https://www.conjur.com.br/2017-abr-01/observatorioconstitucional-supremo-reconhece-juridicidade-afeto-relacoes-familiares $>$ Acesso: Fev/2018.

CHATTER, L.C. União Poliafetiva: A Possibilidade Ou Não De Reconhecimento Jurídico Como Entidade Familiar Dentro Do Contexto Atual Em Que Se Insere A Família Brasileira. Monografia apresentada como requisito para conclusão do curso de pós-graduação em Advocacia Empresarial, Contratos, Responsabilidade Civil e Família, do Instituto Brasiliense de Direito Público/IDP, Brasília, 2015.

FACHIN, R.A.G. Em busca da família do novo milênio. Rio de Janeiro: Renovar, 2011.

FELL, E.T.; SANCHES, J.B. Possibilidade De Reconhecimento Da União Poliafetiva Como Entidade Familiar E Suas Respectivas Implicações Perante O Ordenamento Jurídico Pátrio. Revista de Direito de Família e Sucessões | e-ISSN: 2526-0227| Curitiba | v. 2 | n. 2 | p. 1 - 19 | Jul/Dez. 2016.

FIGUEIREDO, E.L; FERMENTÃO, C.A.G.R. O Núcleo Familiar Poliafetivo e a Dignidade da Pessoa Humana: Análise na Contemporaneidade. In: XXIV Congresso Nacional, CONPEDI, 2015, Aracaju. DIREITO, CONSTITUIÇÃO E CIDADANIA: contribuições para os objetivos de desenvolvimento do Milênio, 2015.

GOEDERT, G. Uniões Poliafetivas: O Reconhecimento Jurídico Como Entidade Familiar. Trabalho de Conclusão apresentado ao Centro de Ciências Jurídicas da Universidade Federal de Santa Catarina, como requisito parcial à obtenção do título de Bacharel em Direito. Florianópolis, 2016.

LEMOS, S.C.A. Os Vínculos Afetivos no Contexto de Acolhimento Institucional: Um Estudo de Campo. Psicologia: Teoria e Pesquisa Vol. 33, 2017, pp. 1-10.

MARTINEZ, W.N. A Poligamia no Direito Previdenciário. São Paulo: LTr, 2016. 
Revista da Faculdade Mineira de Direito | v.21 N.41 244

MEIRA, M.I.C. União Poliafetiva: Aplicação Da Teoria Do Poliamor E Sua Possibilidade Jurídica. Universidade Estadual de Ponta Grossa, 2015. Disponível

<www.simposiodedireitouepg.com.br/2015/down.php?id=1183\&q=1> Acesso: Fev/2018.

MOSCALEWSKY, R. Famílias Poliafetivas: O Reconhecimento Da Realidade Social No Plano Jurídico. Monografia apresentada no Curso de Graduação em Direito, do Setor de Ciências Jurídicas, da Universidade Federal do Paraná, como requisito parcial à obtenção do grau de Bacharel em Direito, Curitiba, 2016.

PEREIRA, I.M.S et al. Poliafetividade - Evolução da Família. RJLB, Ano 2 (2016), $\mathrm{n}^{\circ}$ 3, pp. 773-792.

PEREIRA, R.C. Concubinato e união estável. $7^{a}$.ed. revista e atualizada. Belo Horizonte: Del Rey, 2004

ROSA, A.F; OLIVEIRA, J.S. As relações poliafetivas são permitidas no direito de família brasileiro?. Argumenta Journal Law, Jacarezinho - PR, Brasil, n. 26. p. 197-218, jan/jun 2017.

SANTOS, C.E. O Direito de Família e o Benefício Previdenciário da Pensão por Morte. 2008?. Disponível em <www.buscalegis.ufsc.br/revistas/files/anexos/33220-42168-1-PB.pdf> Acesso: Jan/2018.

SZYMANSKI, H. Teorias e "teorias" de famílias. In: CARVALHO, M. do C. B., (Org.), A Família Contemporânea em Debate. 6. ed. São Paulo, Educ, p.23-27, 2005.

VALLE, T.G.M. (org.). Aprendizagem e desenvolvimento humano: avaliações e intervenções. São Paulo: Cultura Acadêmica, 2009.

VECHIATTI, P.R.I. União Poliafetiva como entidade familiar constitucionalmente protegida. Revista Libertas / Ouro Preto - MG / n. 2, v. 2, Jul./Dez. 2016. 